\title{
Newborn with Hernia Umbilical Cord: A Case Report and Review of Literature
}

\author{
Saif Ghabisha' \\ Faisal Ahmed (1D) ${ }^{2}$ \\ Saleh Al-wageeh (10' \\ Ebrahim Al-shami (D) ${ }^{2}$ \\ Khalil Al-naggar $\mathbb{D D}^{2}$ \\ Ghamdan Obaid ${ }^{3}$ \\ Mohammad Reza Askarpour (iD) ${ }^{4}$ \\ 'Department of General Surgery, lbb \\ University of Medical Science, Ibb, Yemen; \\ ${ }^{2}$ Urology Research Center, Al-Thora \\ General Hospital, Department of Urology, \\ Ibb University of Medical Science, lbb, \\ Yemen; ${ }^{3}$ Department of Orthopedy, lbb \\ University of Medical Science, lbb, Yemen; \\ ${ }^{4}$ Department of Urology, Shiraz \\ University of Medical Sciences, Shiraz, Iran
}

Correspondence: Faisal Ahmed Urology Research Center, Al-Thora General Hospital, Department of Urology, lbb University of Medical Science, Alodine Street, lbb, Yemen Tel +967776089579

Email fmaaa2006@yahoo.com

\begin{abstract}
Cord congenital hernia is a condition in which due to a patent umbilical ring, intestinal components protrude into the umbilical cord. Although post-natal umbilical hernia is not uncommon, its congenital form is an uncommon phenomenon (incidence rate about $0.2 \%$ ) with an excellent post-surgical prognosis. It is frequently misdiagnosed as a small omphalocele. Additionally, if it is undiagnosed at the time of birth, clamping the umbilical cord can cause iatrogenic atresia of the ileum. Hence, during a physical exam, it is mandatory to look carefully for any skin folds in the form of a collar or defects in the umbilical ring or abdominal wall to avoid misdiagnosis. We report a full-term male newborn present with umbilical cord hernia, who underwent successful open surgery, with extra focus on the management and outcome of this disease.
\end{abstract}

Keywords: abdominal wall, congenital abnormalities, omphalocele, umbilical cord hernia

\section{Plain Language Summary}

A congenital cord hernia is a condition in which intestinal components protrude through a patent umbilical ring into the umbilical cord due to a defect in an abdominal wall. In the course of fetal development, physiologically the midgut enters umbilical coelom between the fifth and sixth week of gestation. Then, it returned within 10th to 12 th week of gestation to the abdominal cavity. If any part of the midgut missed the chance to return to the abdominal cavity, the umbilical cord hernia would occur. Compared to post-natal umbilical hernia, Its congenital form is less common, with an incidence rate of 1 in 5000 newborns. We report a full-term male newborn product cesarean section with hernia of the umbilical cord, which was successfully treated with open surgery. The post-operation recovery period was uneventful, and the patient was discharged to home within three days and is currently under follow-up.

\section{Introduction}

Congenital abdominal wall malformation consists of different entities, such as omphalocele, gastroschisis, and the umbilical cord hernia. Congenital umbilical hernia is the rarest form, which is anatomically different from others. ${ }^{1}$ Through the fifth to sixth week of gestation, the midgut physiologically protrudes into the umbilical coelom. Then, it returned within 10th to 12 th week of gestation to the abdominal cavity. If any part of the midgut missed the chance to return to the abdominal cavity, the umbilical cord hernia would occur. ${ }^{2}$ Unlike omphalocele and gastroschisis, umbilical cord congenital hernia could manifest at an early embryological stage and can be reported by ultrasonography in the second trimester. ${ }^{3}$ The incidence rate of it was estimated to be about 1 in 5000 newborns. ${ }^{4}$ The complications accompanying the umbilical cord hernia include malrotation of the intestine, bowel obstruction, 
atresia, and trauma to the intestines due to the accidental clamping of the umbilical cord. ${ }^{5}$

With limited articles on congenital umbilical hernia and lack of physicians' exposure to this phenomenon, it is easily misdiagnosed and under-reported. The general prognosis is good after surgical treatment. We describe a case of congenital umbilical cord hernia in a male newborn, which is treated with open surgery.

\section{Case Report}

A full-term male newborn was born by cesarean section with a gestational age of 38 weeks, born to a 26-year-old Yemeni mother (G2P1). No history of maternal illness or any congenital anomalies in the family. The mother did not receive any multivitamins during pregnancy. No ultrasonography during pregnancy was performed due to a low socioeconomic family.

The neonate had good Apgar scores. The birth weight was $2320 \mathrm{~g}$. Physical examination showed $(9 \mathrm{~cm} \times 8 \mathrm{~cm})$ herniating intestinal loops into the umbilical cord through the umbilical ring with only a thin pearly gray-colored transparent membrane covering a normal red-colored intestine, where normal peristalsis was visible through the membrane. The proximal part of the umbilical ring and cord was surrounded by a $10 \mathrm{~mm}$ strip of skin (Figure 1). The membrane has evidence of abrasions in its outer layer but remains intact. The transillumination test was positive. There were no dysmorphic features, and the rest of the clinical examination was normal. The screening echocardiogram and renal and head ultrasonography (US) were normal. Eight hours after birth and after resuscitation, the baby underwent surgical exploration of the sac with the release of intestinal adhesions, reduced intestinal loops, and an anatomical closure of the umbilical ring without tension (Figure 2). The skin was closed with a purse-string suture. Post-operative recovery was uneventful, and the patient was discharged to home within three days and is now in follow-up (Figure 3).

\section{Discussion}

Being both anatomically and embryologically different from gastroschisis and omphalocele, umbilical cord hernia has the lowest incidence among these abdominal wall anomalies. Umbilical cord hernia appears later during embryonic development, times after peritoneal cavity formation, unlike other two entities that happen around the folding of the lateral folds in the earliest stages of embryonic. $^{6}$

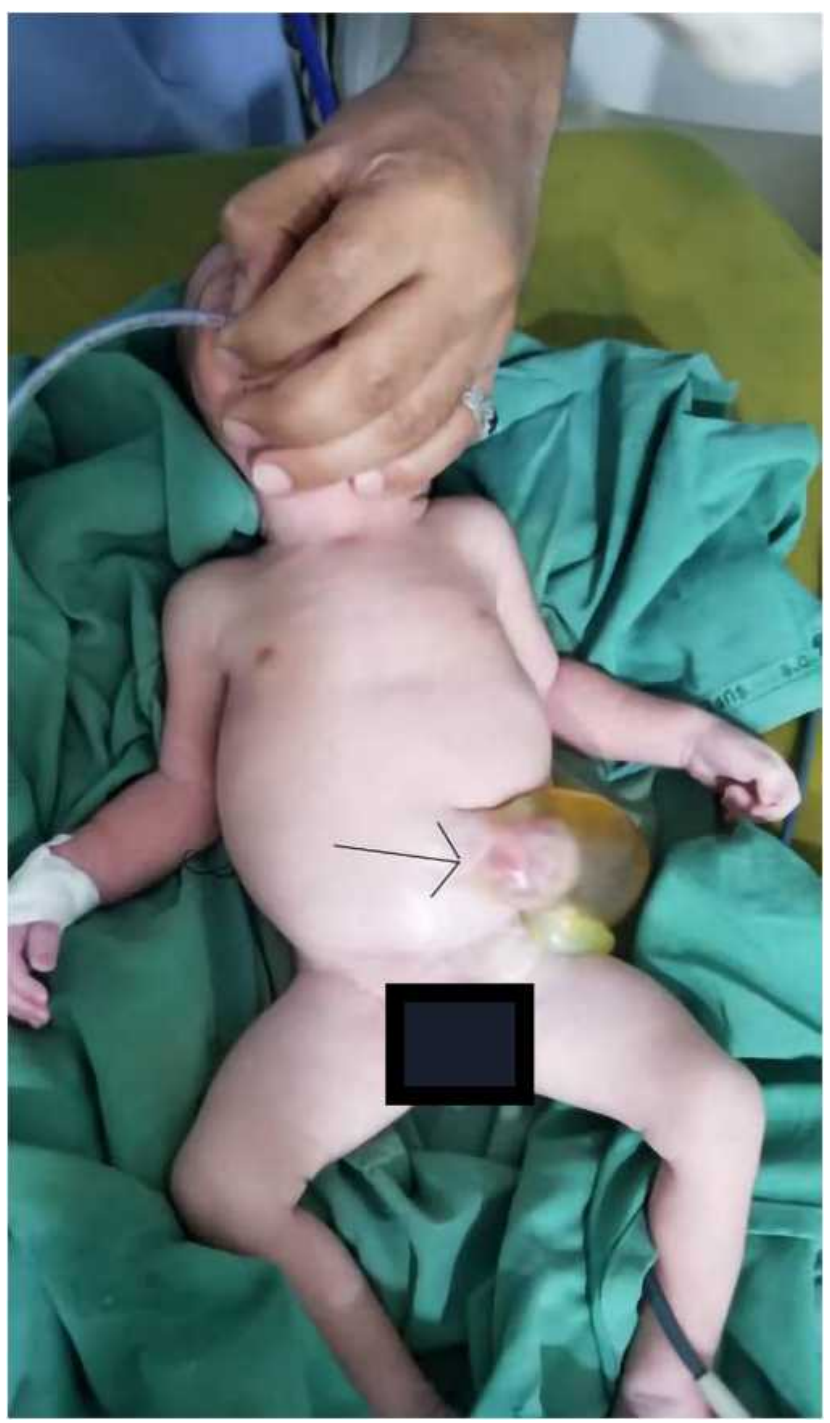

Figure I Showing an omphalocele sac $9 \times 8 \mathrm{~cm}$ containing intestine and umbilical cord cyst.

In the course of normal fetal growth, physiologically bowels, after development had to migrate from the umbilical cord to the abdominal cavity. Any disruption in the path of bowel and viscera migration or failure of the umbilical ring closure leads to a congenital hernia of the umbilical cord. The umbilical ring and proximal part of the cord are covered with skin in this phenomenon. Omphalocele minor, on the other hand, is a condition in which a true abdominal wall defect is present. ${ }^{7,8}$ If the herniation is caused by the abdominal wall para-umbilical defect, this type of herniation is called Gastroschisis which is mostly in the right-side. Abdominal organs or various segments of the bowel may herniate from this small (mostly less than $4 \mathrm{~cm}$ in diameter) abdominal wall defect. ${ }^{8}$ 


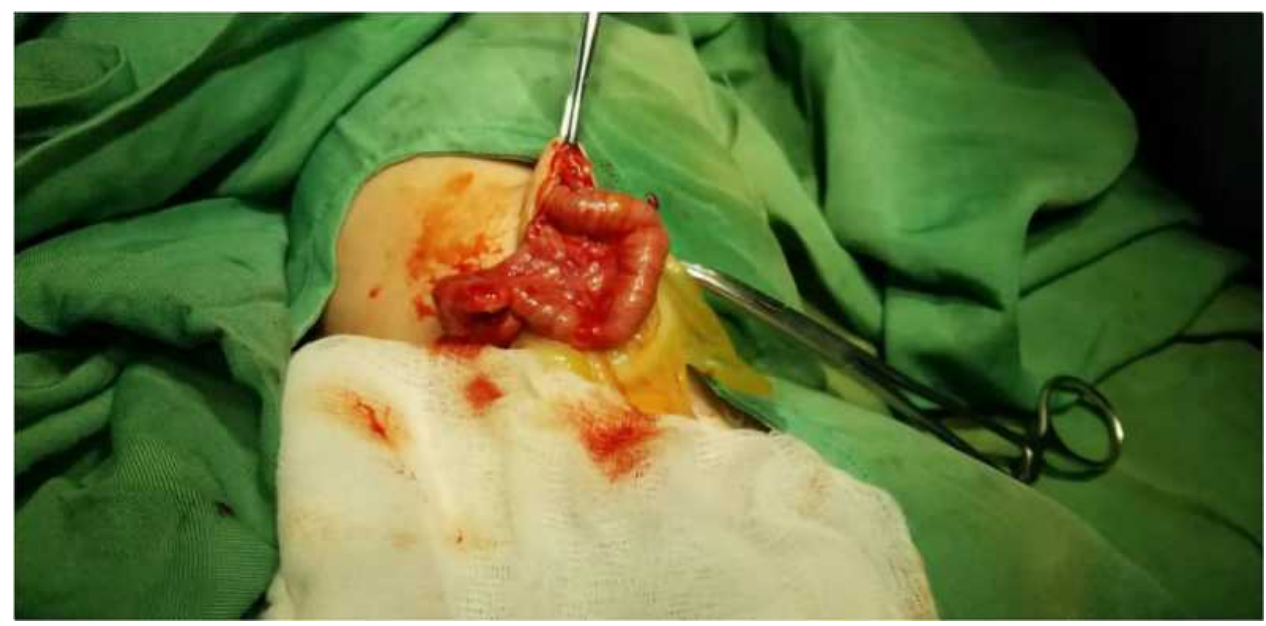

Figure 2 Showing the sac with dilated distal ileum and ileo-cecal junction.

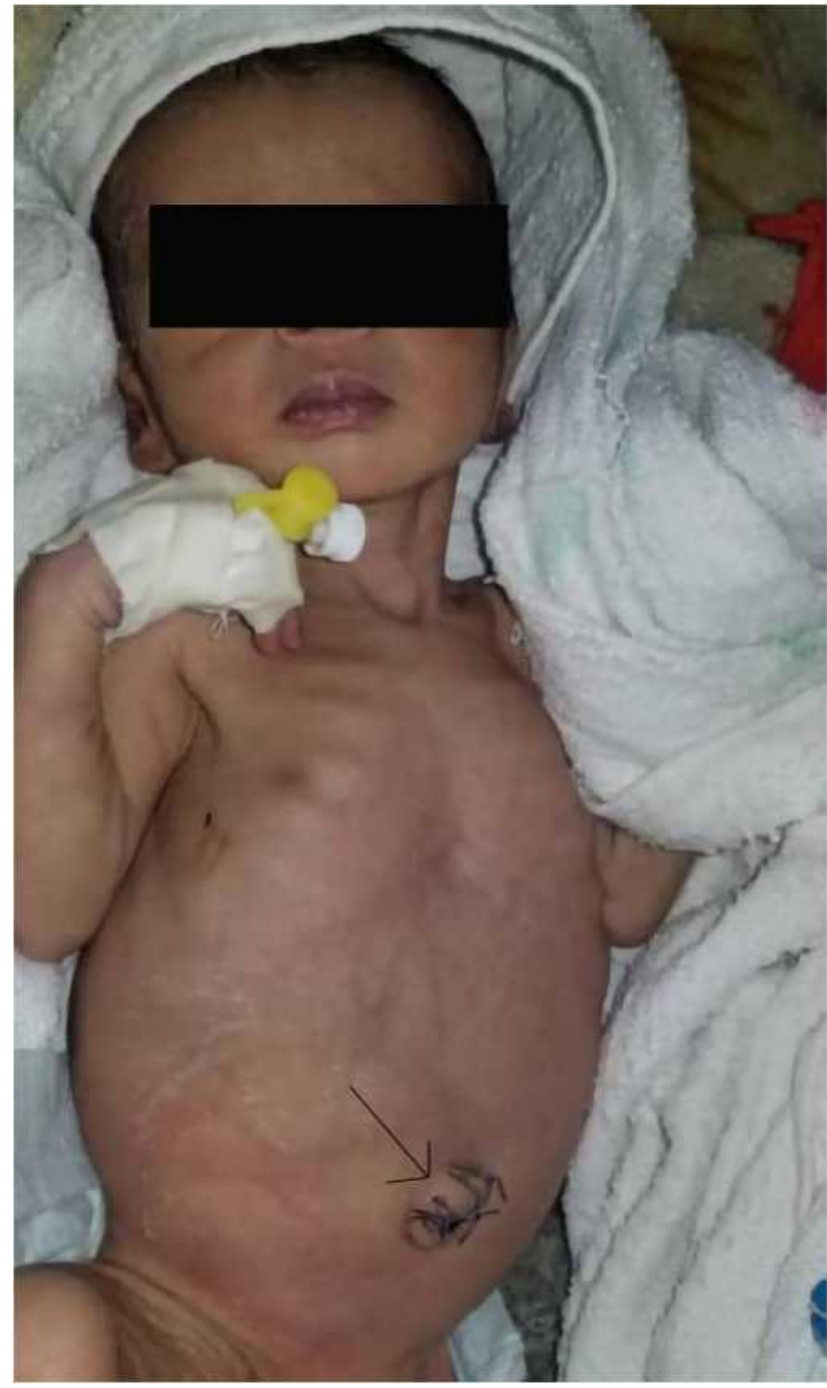

Figure 3 Showing the baby in follow-up period with successful outcome.
During a physical exam, it is mandatory to look carefully for any skin folds in the form of a collar or defects in the umbilical ring or abdominal wall to avoid misdiagnosis. Any abnormal cord's base thickness companies with even a small fistula opening to its side should prompt the physician to consider the presence of these anomalies. If undiagnosed, clamping the umbilical cord after birth can cause iatrogenic atresia of the ileum. ${ }^{6}$

There are four types of umbilical cord congenital hernia: Type 1 is a simple hernia into the cord without any associated complications; Type 2 is related to intestinal obstruction; Type 3, a distinct variety associated with mucosal prolapse; and Type 4 is associated with evisceration., ${ }^{5,9}$ Other associated anomalies include persistent cloaca, Meckel's diverticulum, persistent vitellointestinal duct, bowel atresia, short bowel syndrome, and stenosis. Glaucoma, congenital heart disease, cleft lip, and cleft palate are fewer common anomalies associated with the congenital umbilical hernia. ${ }^{10}$ Till now, no underlying genetic disorders are reported that accompany the cord hernia. ${ }^{11}$

When omphalocele is diagnosed prenatally, it may make parents severely stressed. If a child with a high chance for normal life expectancy after surgical treatment is aborted, it is unfortunate for both family and society. A higher level of awareness among the caregivers may stop such tragedies by preventing poor decision-making. ${ }^{6}$

Recently, hernia of the umbilical cord could be diagnosed in prenatal with prenatal ultrasonography and magnetic resonance imaging (MRI). ${ }^{5}$ 
The young maternal age at birth and the low socioeconomic level are the primary maternal risk factors associated with pregnancy that can contribute to the increased omphalocele and gastroschisis occurrence. Additionally, it was reported that multivitamins intake in pregnancy is associated with a $60 \%$ risk reduction for symptomatic omphalocele. ${ }^{12}$ Stabilization and urgent surgical exploration and reduction of the sac content are mandatory to rule out associated intestinal atresia and other abnormalities, which were performed in our case and mentioned in other articles. ${ }^{3,13}$

\section{Conclusions}

The congenital umbilical hernia is a rare phenomenon, with a good prognosis after reduction surgery. A wrong diagnosis can cause severe stress for parents, encouraging tragic abortions. If undiagnosed during delivery, severe intestinal damage can occur by clamping the cord, so it is essential to increase medical staff knowledge and alertness toward this diagnosis to prevent unnecessary abortions and morbidities.

\section{Ethical Consideration}

This study was approved by the ethics committee of Ibb University of Medical Sciences.

\section{Consent for Publication}

The patient parents understood that clinical data of the baby is going to be utilized for publication purposes and they agreed on that. The patient parents gave consent to use data including the images of the baby for publication.

\section{Funding}

There is no funding to report.

\section{Disclosure}

Dr Ghamdan Obaid reported a patent, whether planned, pending or issued, broadly relevant to the work. The authors declare that they have no other potential conflicts of interest for this work.

\section{References}

1. Ledbetter DJ. Congenital abdominal wall defects and reconstruction in pediatric surgery: gastroschisis and omphalocele. Surg Clin North Am. 2012;92(3):713-727, x. doi:10.1016/j.suc.2012.03.010

2. Haas J, Achiron R, Barzilay E, Yinon Y, Bilik R, Gilboa Y. Umbilical cord hernias: prenatal diagnosis and natural history. $J$ Ultrasound Med. 2011;30:1629-1632. doi:10.7863/jum.2011.30.12.1629

3. Pal K. Congenital hernia of the umbilical cord associated with extracelomic colonic atresia and perforation of gut in a newborn. Afr J Paediatr Surg. 2014;11:74-76. doi:10.4103/0189-6725.129241

4. Burns CW, Ogryzlo MA. Congenital hernia into the umbilical cord; two cases, one associated with persistent cloaca. Can Med Assoc J. 1938;39:438-441.

5. Mirza B, Saleem M. Hernia of umbilical cord with congenital short gut. J Neonatal Surg. 2014;3:26. doi:10.47338/jns.v3.88

6. Raicevic M, Filipovic I, Sindjic-Antunovic S. Hernia of the umbilical cord associated with a patent omphalomesenteric duct. $J$ Postgrad Med. 2017;63:58-59. doi:10.4103/0022-3859.198157

7. Mirza B, Mirza A, Hashim I, Saleem M. Hernia of umbilical cord: report of three unusual cases. $J$ Neonatal Surg. 2015;4:16. doi: $10.47338 /$ jns.v4.169

8. Wilson RD, Johnson MP. Congenital abdominal wall defects: an update. Fetal Diagn Ther. 2004;19:385-398. doi:10.1159/000078990

9. Mirza B, Ali W. Distinct presentations of hernia of umbilical cord. J Neonatal Surg. 2016;5:53. doi:10.21699/jns.v5i4.400

10. Keshorjit Singh I. Hernia of umbilical cord associated with cleft lip and palate, and congenital glaucoma. J Neonatal Surg. 2015;4:49. doi:10.47338/jns.v4.461

11. Gopagondanahalli K, Chang A, Nataraja R, Tan K, Chandran S, Saiprasad T. Congenital hernia of umbilical cord masquerading as umbilical cyst and omphalocele on antenatal scans. Med J DY Patil Vidyapeeth. 2020;13:285-287. doi:10.4103/mjdrdypu.mjdrdypu_91_19

12. Chircor L, Mehedinţi R, Hîncu M. Risk factors related to omphalocele and gastroschisis. Rom J Morphol Embryol. 2009;50:645-649.

13. Sharma D, Murki S, Pratap T. A newborn with omphalocele and umbilical cord cyst: an interesting entity. Iran $J$ Pediatr. 2014;24:449-450.
Open Access Surgery

\section{Publish your work in this journal}

Open Access Surgery is an international, peer-reviewed, open access journal that focuses on all aspects of surgical procedures and interventions. Patient care around the peri-operative period and patient outcomes post-surgery are key topics for the journal. All grades of surgery from minor cosmetic interventions to major surgical procedures are covered. Novel techniques and the utilization of new

Submit your manuscript here: https://www.dovepress.com/open-access-surgery-journa instruments and materials, including implants and prostheses that optimize outcomes constitute major areas of interest. The manuscript management system is completely online and includes a very quick and fair peer-review system, which is all easy to use. Visit http://www.dovepress.com/testimonials.php to read real quotes from published authors. 